\title{
Dam Break Analysis on a River System
}

\author{
L. Carballada \\ Associate Professor, Concordia University, Montréal \\ Specialist, Hydro-Québec, Montréal
}

\section{Introduction}

Dam break analysis has been an important topic of research and development on fluid mechanics and hydraulics for almost a century. Since the Ritter solution [15] up to the work of Hunt [12], the topic still has unexplored possibilities that come up as the research on the topic goes on $[6,7,10,11,13,14]$. The reason for the actual renewed interest of research on this topic is that the results of a dam break analysis are basic to any civil protection strategy [1] concerning people living on the area down-stream of the dam.

Due to the development of computer packages $[1,7$, $10,13]$ able to simulate the mechanics of the breach as well as the routing of the flood downstream of the breached dam, the tools to simulate the breach and the impact close and far away from the dam became available. To simulate dam breaching, physical modelling is not advisable due to the prohibitive cost when the study is supposed to cover a long river reach; so mathematical modelling on computer is the standard practice in this kind of analysis.

Public awareness of the dam safety problem as well as the loss of life following various catastrophic failures such as Malpasset, Teton, etc., motivated government and related public utilities to do something about the problem.

The French power utility E.D.F. has done pioneering work on the subject, analysing all French dams. The U.S. Senate with the Sam Safety Act provided the momentum in the U.S. to analyse all hazard impact dams.

The difference between the U.S. and France is that in the U.S., only the small dams have been analysed while in France all the dams have been considered. In Canada, only the government owned Quebec power utility Hydro-Québec, is doing systematic dam break analysis of its schemes.

The following symbols are used in this paper :

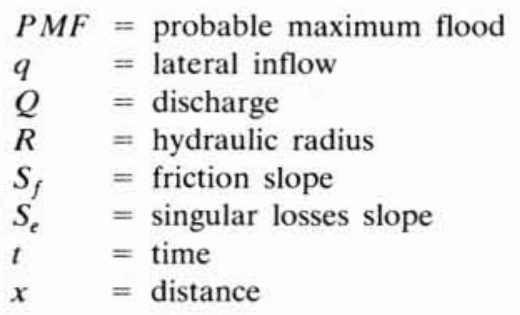

\section{Analyse d'une rupture de barrage sur une rivière aménagée}

Une rivière complètement aménagée a tous les barrages nécessaires pour obtenir son plein potentiel économique d'un point de vue optimal. Si on fait une analyse de rupture, tous les barrages doivent être considérés. La rivière considérée dans cette étude a huit barrages et quatre affluents. Cette analyse nous éclaire sur le comportement de la rivière dans un contexte de bris de barrage. La crue prend 28.5 h pour se propager et sa durée près du maximum est d'une semaine. L'influence de la rugosité et l'état du lit de la rivière ont été pris en compte. La volatilisation de barrages est instantanée; cette hypothèse étant trop sévère, elle est compensée par le fait qu'on ne tolère pas le déversement sur chaque barrage. 


\section{Theory}

The dam break phenomenon is essentially a transient problem with two main aspects :

a) Simulation of the breach.

b) Routing of the resulting outflow in the valley downstream from the dam.

The mathematical formulation of the problem is done with the Saint-Venant equations in a one-dimensional form. These equations represent the conservation of momentum and mass of the water ; they read as follows :

$$
\begin{aligned}
& \frac{\delta Q}{\partial t}+\frac{\partial\left(Q^{2} / A\right)}{\partial x}+g A\left\{\frac{\partial h}{\partial x}+S f+S e\right\}=0 \\
& \frac{\partial Q}{\partial x}+\frac{\partial\left(A+A_{0}\right)}{\partial t}-q=0
\end{aligned}
$$

where: $\quad S f=\frac{n^{2}|Q| Q}{2.2 A^{2} R^{4 / 3}} \quad$ (friction losses),

$$
S e=\frac{K e \Delta(Q / A)^{2}}{2 g \Delta x} \quad \text { (singular losses), }
$$

$Q=$ discharge,$\quad A=$ area,$t=$ time,$\quad x=$ longituginal coordinate, $g=$ acceleration of gravity, $h=$ water elevation, $q=$ lateral flow, $A_{0}=$ storage area, $n=$ Manning's coefficient and $R=$ hydraulic radius, $K_{e}=$ singular loss coefficient.

These equations have no closed form solution on a river of arbitrary shape, so numerical techniques are used.

Various authors $[1,7,10,13]$ have obtained the solution to the problem with different numerical schemes.

The study presented here follows the approach described in reference [1] which means that internal singularities such as hydraulic jumps and joining rivers are considered in the analysis as well as supercritical and subcritical slopes.

\section{Statement of the problem}

A harnessed and power developped river has in general as many dams as are needed for the economic and optimal development of all its full potential to provide energy or other side benefits such as irrigation or flood mitigation.

The targets on a dam-break analysis are the populated areas with risk of loss of life and any other strategic installation like a nuclear power plant, a bridge, a dam etc., that can be affected by the resulting flood.

The case presented below analyses a complete river system with eight dams. The first dam upstream is of the storage type containing $90 \%$ of the complexe active storage ; the other dams just turbine the releases from the storage dam and provide short term storage.

Once the populated zones and other sensitive areas have been identified, a choice has to be made on which one of the dams is going to be breached and how.

Depending on the position of the impact areas, as well as the dam function on the scheme, the choice will vary from one river to another and each case must be examined with a different rationale. For the case under consideration, the impact areas are situated at the downstream end of the river while $90 \%$ of the water volume is stored in the most upstream reservoir. Any analysis that does not consider the most upstream dam in this case will provide an unconservative picture of the impact, making the whole exercice of limited value since the results will reflect a downgraded impact as far as severity and duration of the phenomena are concerned.

So here we come to the conclusion that multiple dambreak $[1,5]$ or cascade dam-break analysis is needed in certain cases to evaluate the flood impact in a reasonable manner.

\section{Initial state and breach sequence}

The state of the river system [2] as the simulation starts must be defined in advance as well as the input to the system during the simulation process, i.e. upstream and lateral inflows to the river.

The hydrology of the watershed must be known to see if the storage of the reservoirs is able to withstand a sizable hydrologic input with minor changes in water levels. If this is not the case, an hydrologic input defined in advance must be considered, it could be the PMF.

On the other hand, if a sizable hydrologic event is accepted by the river system without major changes, this implies that the storage is much greater than the water volume of the hydrologic event. This event can be neglected since this will be a small percentage of the water volumes released during the simulation process [2].

The sequence of breach is the same as the location sequence of the dams on the river proceeding in the downstream direction.

For the study considered here [2], we assume complete volatilization of the structure as the wave front reaches the structure. This hypothesis could be unconservative since it makes sense to think that overflowing of the structure will take place before the final collapse, but since the biggest discharges are behind the wave front, the fact of breaking the structure as the front arrives gives information about the individual effect of breaking each structure in the vicinity of the dam on a short period before a sizable amount of the flood produced [2] by the upstream breached dams reaches the dam under consideration.

Figure 1 shows the study reach for the eight dams, the abscissa is the axis of the river and the ordinate is the elevation of the river bottom and its stage at the start of simulation.

\section{Description of the river system}

This scheme has eight dams that are described on table 1, the most upstream dam is identified as number 1 which contains $92 \%$ of the water volume of the whole system. The other dams are given by a number up to number 8 at the downstream end. The location of each dam with 


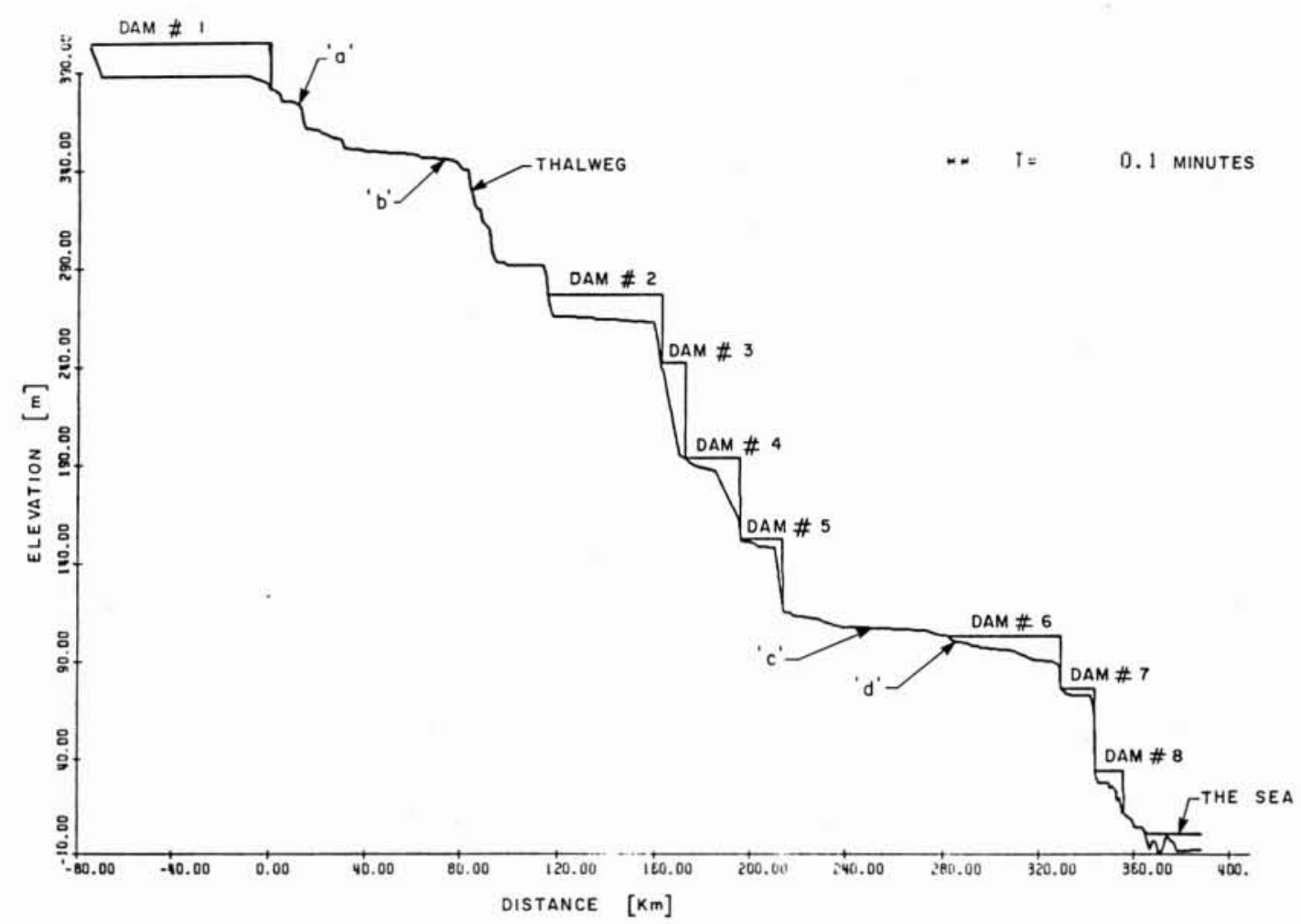

1. River system configuration with tributaries location at the beginning of the simulation.

Table 1. Dams and reservoirs parameters.

\begin{tabular}{c|c|c|c|c|c|c}
\hline \hline Dam number & $\begin{array}{c}\text { Storage } \\
10^{6} \mathrm{~m}^{3}\end{array}$ & $\begin{array}{c}\text { Reach storage } \\
\text { up to the dam } \\
10^{6} \mathrm{~m}^{3} \\
(3)\end{array}$ & $\begin{array}{c}\text { Elevation } \\
\text { in metres } \\
(2)\end{array}$ & $\begin{array}{c}\text { Reservoir length } \\
\text { on kilometres }\end{array}$ & $\begin{array}{c}\text { Location of each dam } \\
\text { w.r.t. dam number } 1 \\
(1)\end{array}$ & $\begin{array}{c}\text { Foot dam elevation } \\
\text { in met res }\end{array}$ \\
\hline 1 & 8567 & 8567 & 405.08 & 75 & 0 & $(7)$ \\
2 & 452 & 9019 & 275.84 & 46 & 162.0 & 381.00 \\
3 & 76 & 9095 & 241.71 & 10 & 172.0 & 240.79 \\
4 & 43 & 9138 & 192.94 & 22 & 195.0 & 193.55 \\
5 & 35 & 9173 & 151.79 & 17 & 213.0 & 162.15 \\
6 & 108 & 9281 & 102.60 & 46.5 & 328.8 & 121.92 \\
7 & 13 & 9294 & 75.60 & 13.0 & 343.4 & 85.65 \\
8 & 30 & 9324 & 35.50 & 11.5 & 355.4 & 64.31 \\
\hline \hline
\end{tabular}

respect to the most upstream one is indicated on column (6) of table 1 .

The reach from dam number 1 up to dam number 8 is
$388 \mathrm{~km}$ long, the position on the valley of points of interest such as dams, tributaries, is given to better qualify the site on figure 1 . 


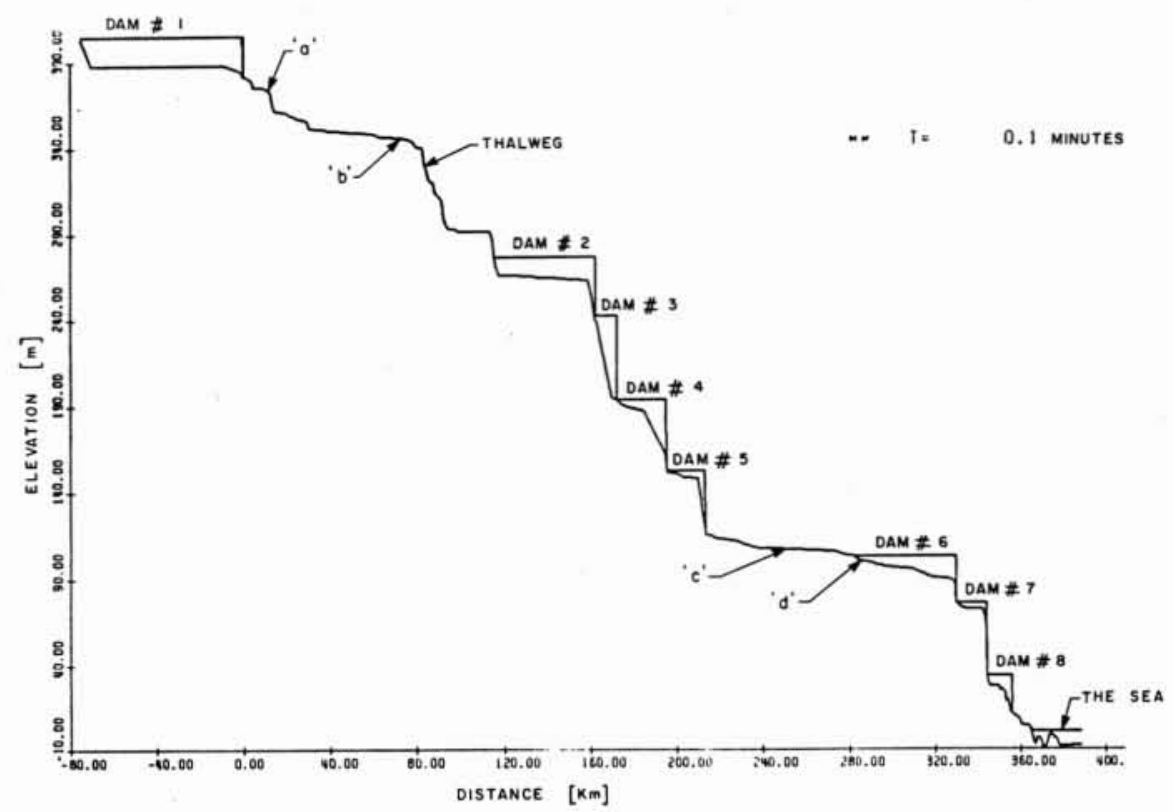

1. River system configuration with tributaries location at the beginning of the simulation.

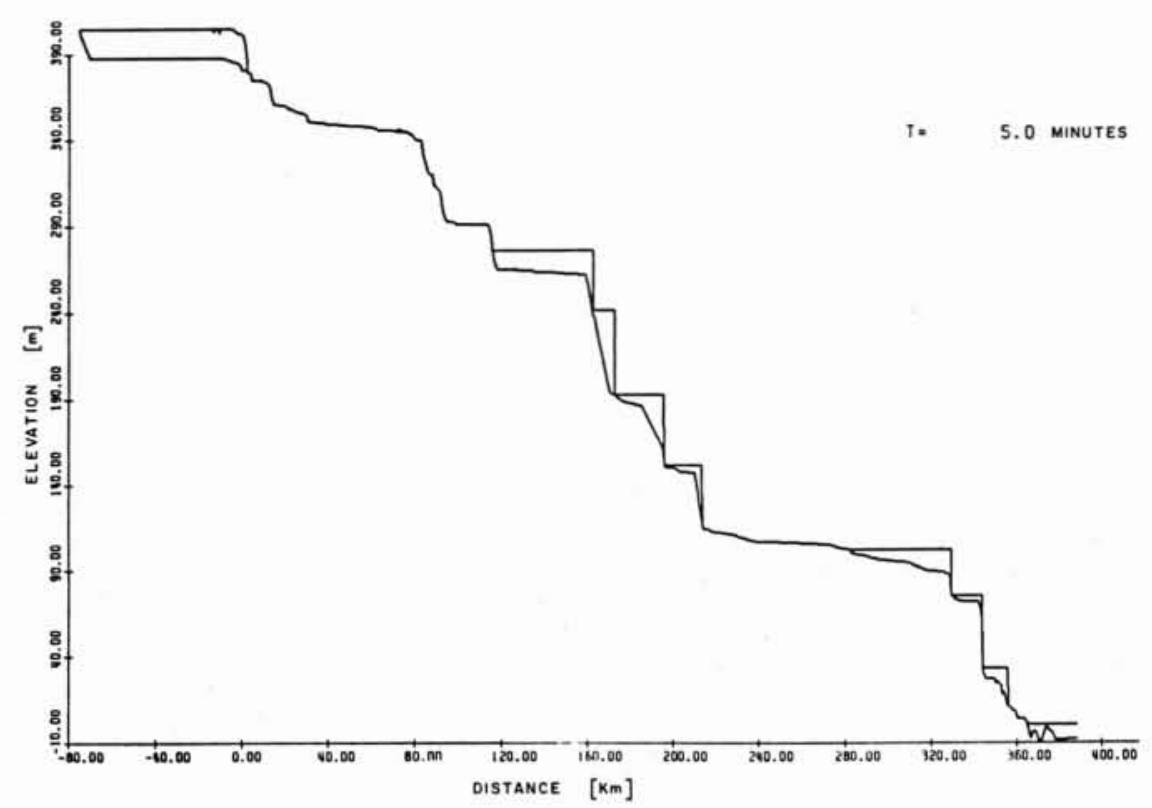

2. River state 5 min after breach of dam \#1.

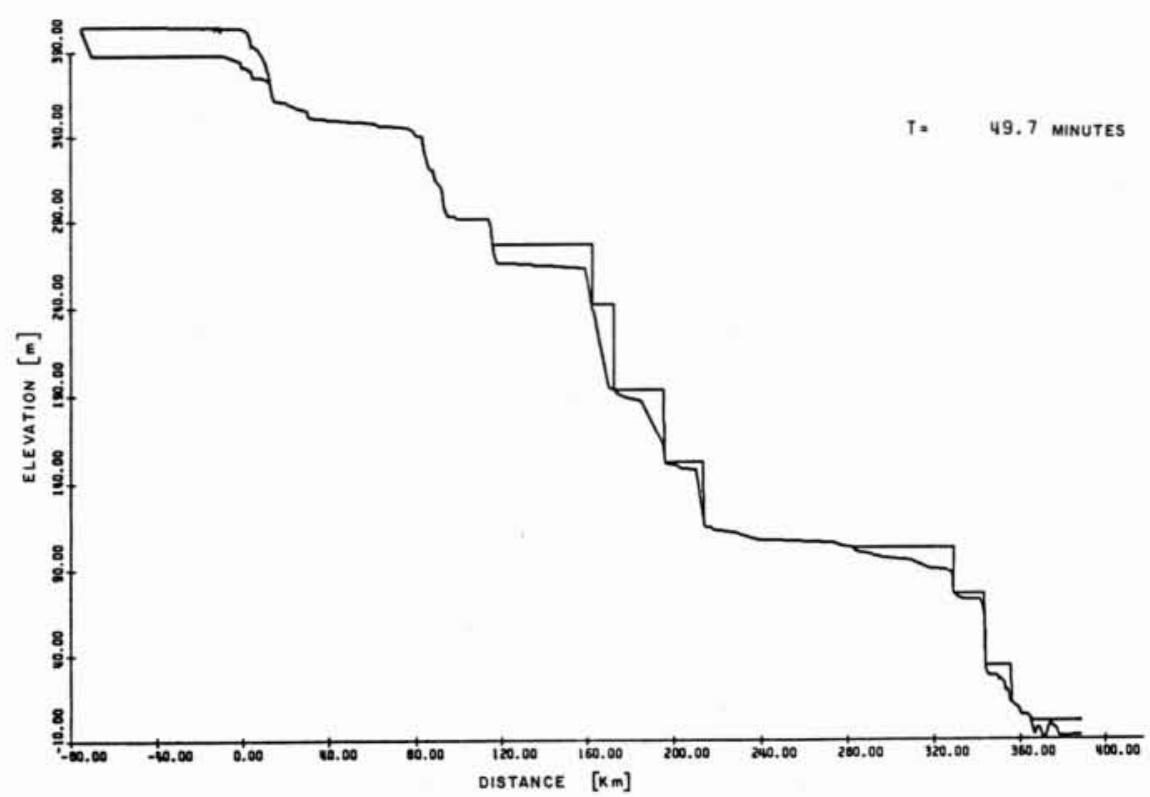

3. River state 49.7 min since the beginning of the simulation. 


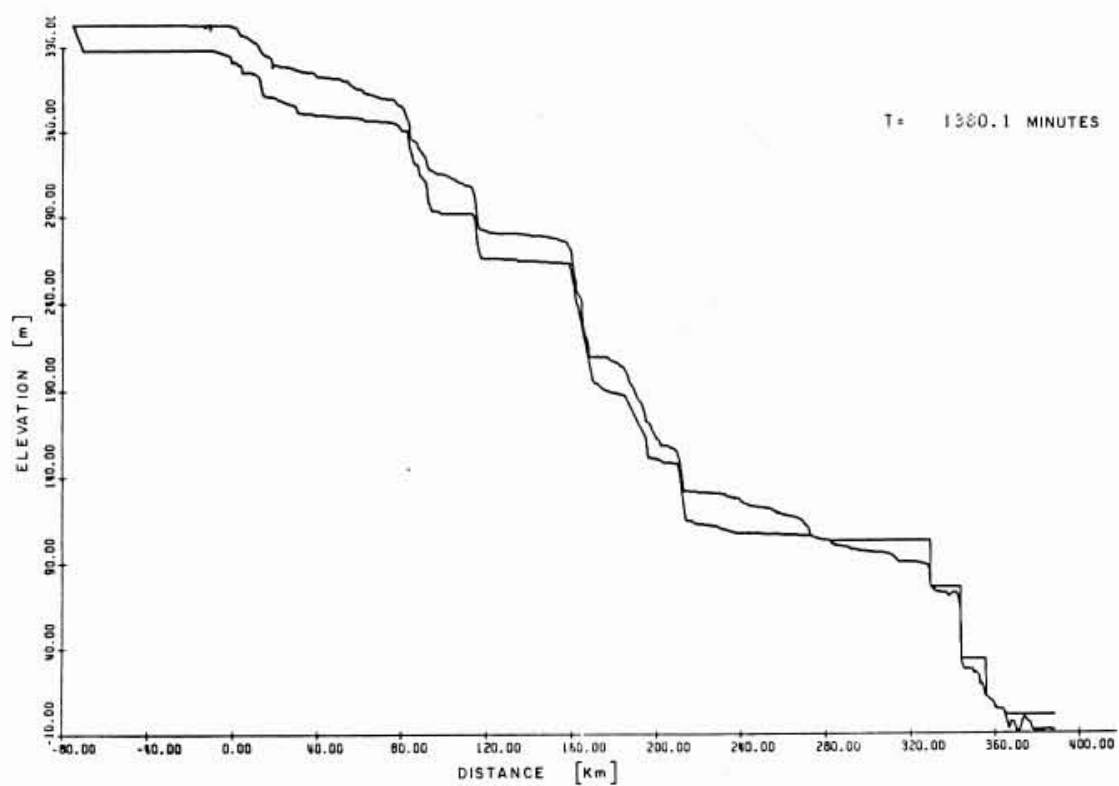

4. River state 1380.1 min since the beginning of the simulation.

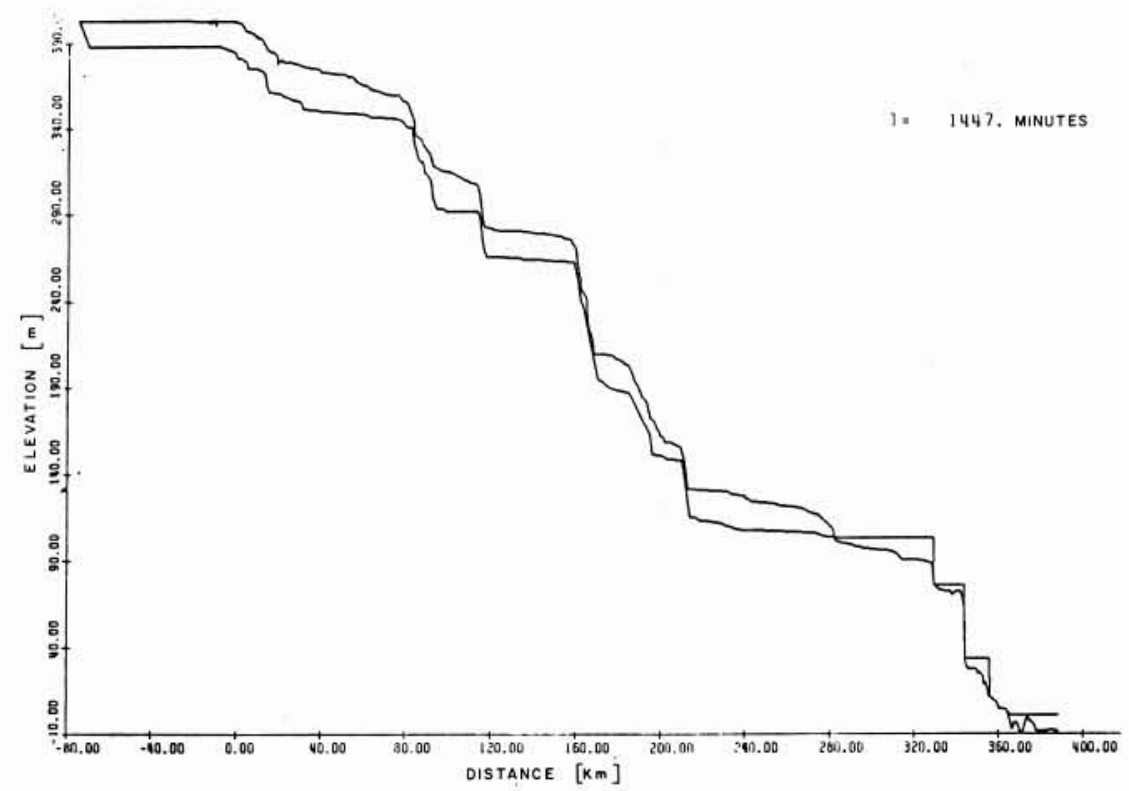

5. River state 1447.0 min since the beginning of the simulation.

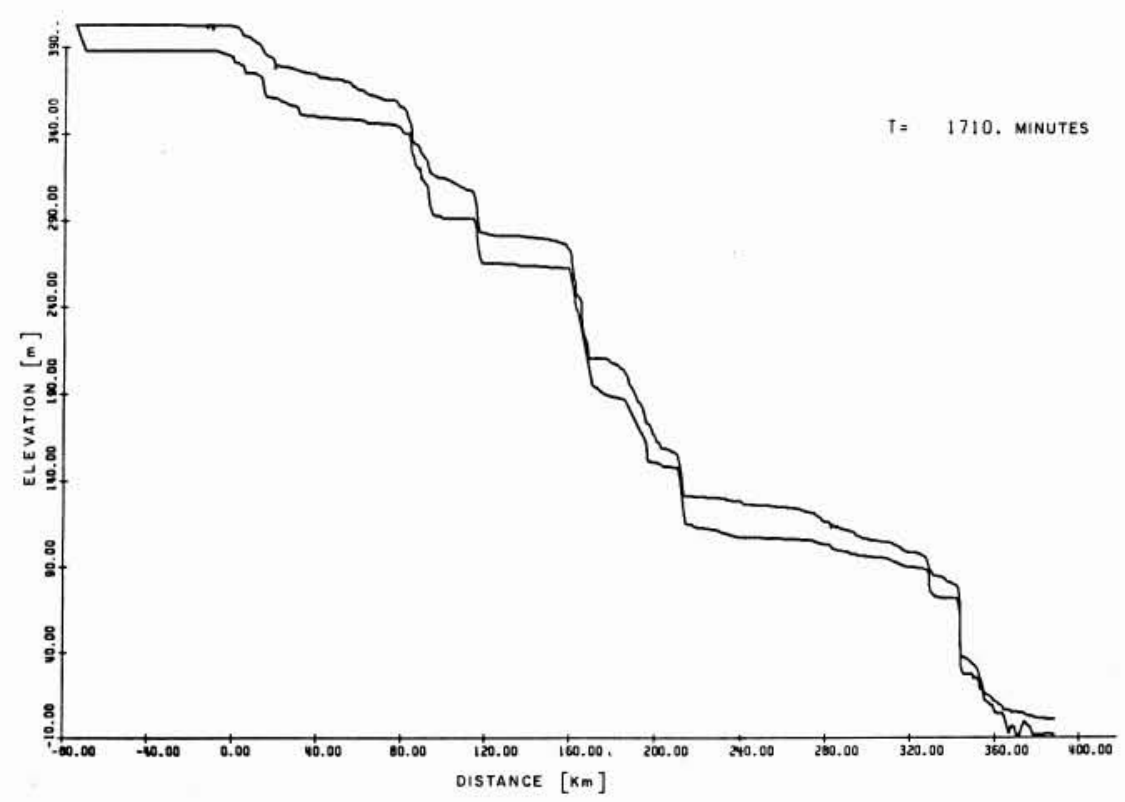

6. River state 1710.0 min since the beginning of the simulation, all the dams have been breached. 


\section{The data}

The system is composed of the main reach of the river and the four tributaries identified in figure 1 as $a, b, c$ and $d$.

The topography of the valley, the longitudinal profile and the transversal sections have been taken from maps to the 1: 50000 scale.

The transversal data sections are given every kilometer or closer if expansions or contractions exist. At each dam, two transversal sections are given upstream and downstream of the structure. Small modifications are made at sharp variations of geometry to make the variation more gradual.

The main parameters of the dams are given on table 1 such as dam location, bottom elevation, dam stage, storage and reservoir length.

Considering that the most upstream reservoir is $75 \mathrm{~km}$ long, the total length of the main reach is $463 \mathrm{~km}$.

Dam number 1 , the most upstream dam, is located at kilometer zero, which means that the start of the reach is at kilometer -75 and the end of the reach is at kilometer 388.

The valley roughness is expressed by an Strickler coefficient. The values have been chosen considering the condition of the valley, populated area, forestation, etc. Roughness values ranging from 20 to 35 have been chosen, depending on the information obtained from the maps.

Table 1 also shows the elevation of the different reservoirs of the complex. The reservoirs are considered horizontal and small dry bed reaches can exist depending on the position on the reach of the reservoir tail with respect to the preceeding reservoir.

A wet bed is assumed at the downstream end of the reach where the main river joins the sea.

\section{Procedure}

The simulation starts at the instant $t=0$ with the total instantaneous breaching of dam number 1 at kilometer zero.

The computer code used for the simulation solves the Saint-Venant equations by a finite differences explicit method a Lax-Wendroff scheme (1) with a fixed $\Delta x=200 \mathrm{~m}$ and $\Delta t$ changing at every step to optimise the computer time setting the time increment always close to the Courant number stability limit.

The downstream boundary condition is the wave front, since movement of the wave front starts at kilometer zero, at the beginning of the simulation, the active computing reach is not long, its length progressing with the wave front movement.

The possible hydraulic jumps as well as its motion are considered in the simulation process.

Figure 1 shows the initial configuration of the valley with the bottom profile and all the reservoirs in place. The simulation started $0.1 \mathrm{~min}$ ago and only dam number 1 has been breached. Since this time is very short, figure 1 gives the information concerning the initial state of the river system before the dam break simulation started. To identify the dams, table 1 gives on column (1) and column (6) the number and the position of each dam. In figure 1 dam number 1 is the most upstream one.

Figure 1 is self-explanatory. Nevertheless, we can say that the vertical lines represent the dam structure, the horizontal lines, water stages and the continuous lines the thalweg of the river.

The horizontal lines between kilometers 360 and 400 is the sea level assumed in the study.

The upstream boundary condition is given as a small flow hydrograph to the most upstream reservoir.

The simulation progresses with time as the wave front moves downstream, once the wave front reaches the limits of the domain, the simulation stops unless another boundary condition is provided.

The breach hypothesis is the volatilisation of each structure as the wave front reaches it.

\section{Analysis of results}

The results of the study are given as discharge and water stage at each site versus time of occurrence.

Figures 1 to 6 show the whole river stage at $0.1,5.0$, $49.7,1380.1,1447.0$ and $1710.0 \mathrm{~min}$ since the simulation started.

Observing these figures we can see the progression of the wave front and its shape to some extent. The exact position of the wave front on figures 1 to 6 is 150.0 , $2000.0,12700.0,272700.0,282300.0$ and $388000 \mathrm{~m}$.

The time $1710 \mathrm{~min}$ when the front reaches the kilometer 388 means the end of the study ; the first release of water from dam number 1 takes $28.5 \mathrm{~h}$ to reach the sea.

The discharge at dam number 1 has a peak close to $24000 \mathrm{~m}^{3} / \mathrm{s}$ after one hour, further decreases to $20000 \mathrm{~m}^{3} / \mathrm{s}$ in $10 \mathrm{~h}$, than becomes almost stable for the remaining simulation time.

The reservoir dam number one being relatively shallow, $24 \mathrm{~m}$ in depth (table 1), and considering its breach hydrograph, there is a control limiting the discharge to a representative value of $20000 \mathrm{~m}^{3} / \mathrm{s}$. This effect could have been foreseen considering the relatively small depth (table 1, column 4) and narrow transversal section of dam number 1 .

Since the total storage of dam number 1 is 8567 millions cubic meters, the mean hydrograph at the dam site is a constant discharge of $20000 \mathrm{~m}^{3} / \mathrm{s}$. The reservoir will sustain this discharge during 5 days. Considering the $28.5 \mathrm{~h}$ that the water takes to travel from dam number 1 to the end of the reach it is reasonable to assume that at some moment during the five day period required to empty reservoir number one, a steady discharge of $20000 \mathrm{~m}^{3} / \mathrm{s}$ will be established on the whole reach.

Figures 7 and 8 show the hydrograph at selected sites. Each figure shows the discharge on $10^{2} \times \mathrm{m}^{3} / \mathrm{s}$ versus the simulation time in minutes. The time reference for all these hydrographs is the beginning of simulation at dam number $1 t=0$.

The time shown at the start of the rising limb of the hydrograph is the time at which the wave front reaches the site. If the site is a dam, this time coincides with its total failure as indicated on the breach hypothesis. 


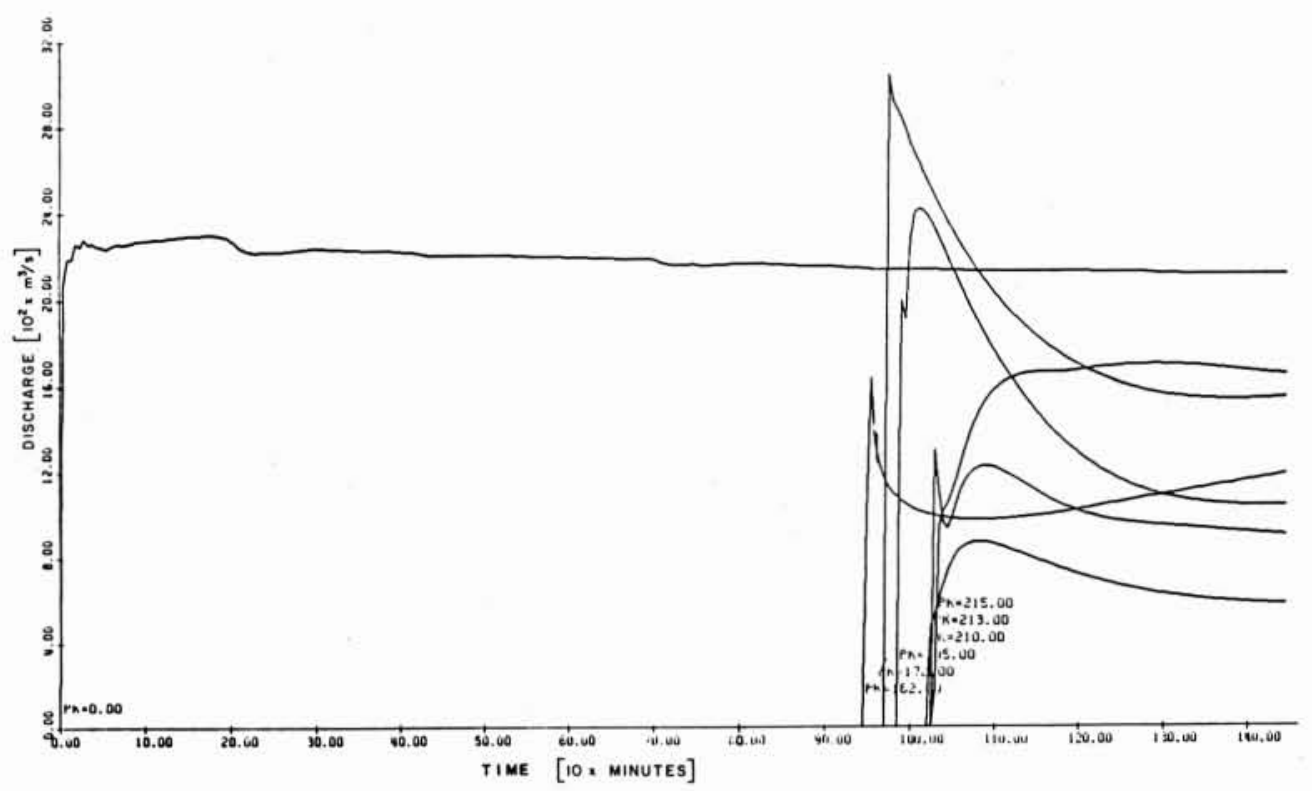

7. Discharge in $\left(10^{2} \mathrm{~m}^{3} / \mathrm{s}\right)$ versus time in $(10 \mathrm{~min})$ at chosen points.

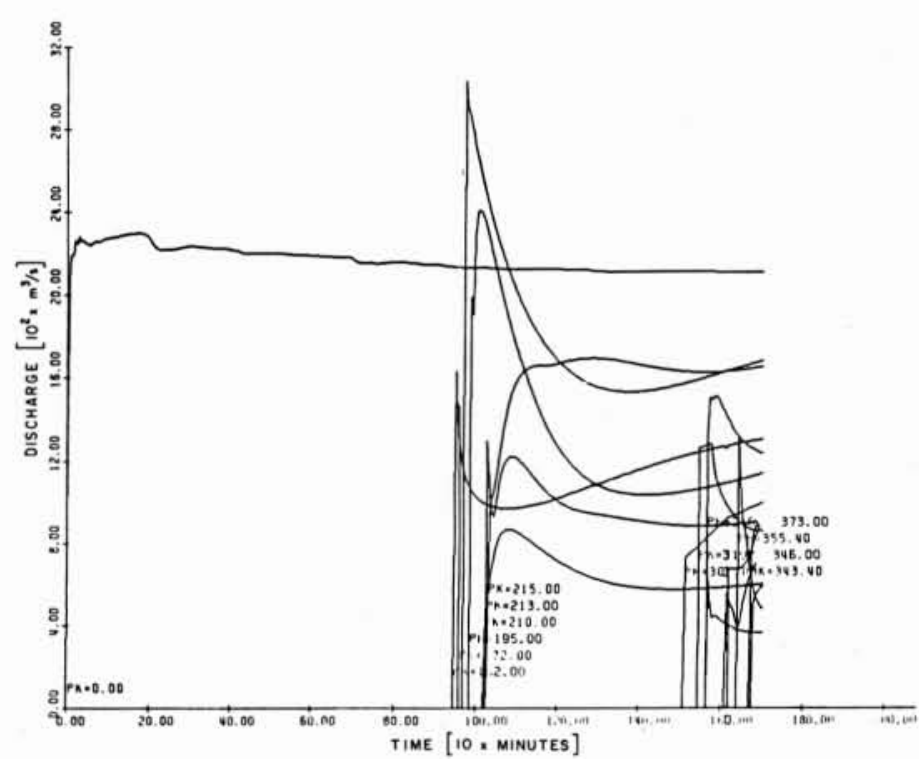

8. Discharge $\left(10^{2} \mathrm{~m}^{3} / \mathrm{s}\right)$ versus time $(10 \mathrm{~min})$ at kilometers $0.0 . \ldots, 303,319,320,343.4,346.0,355.4,373$.

Due to the length of the time scale, only the short period comprising the rise and fall of hydrograph is shown on these figures.

Figure 7 has been already explained. It shows the behaviour of dam number one with, some numerical perturbations and the $24000 \mathrm{~m}^{3} / \mathrm{s}$ discharge with the stabilisation around $20000 \mathrm{~m}^{3} / \mathrm{s}$.

Figure 8 shows the hydrographs for the sites located between kilometer 162 and 215 .

The dam located at kilometer 172 , dam number 3 shows the biggest discharge on the whole reach $120000 \mathrm{~m}^{3} / \mathrm{s}$ but decreases very fast, in less than $20 \mathrm{~min}$.

For the sites located at kilometer 192 and 213 , i.e. the dams numbers four and five, the hydrographs have two peaks, one due to its own failure and the other one due to the phase shift between the occurrence of the wave front and the maximum discharge of the flood resulting from the upstream breached dams.

Figure 8 also shows the hydrographs at the downstream site of the reach. On this figure as well as on the other figures commented above, the sharp rise hydrograph represents either dam sites or locations very close to dams. On this figure the phase shift between the arrival of the wave front and the peak discharge of the flood is more clear for the dam located at kilometer 355, the last dam. We obtain an hydrograph with very small influence of the upstream dams for the time considered in the simulation. For the other dams of figure 8 ; the "sag " curve pattern due to the upstream flood is clearly seen but not to the full impact because the discharge does not reach the $20000 \mathrm{~m}^{3} / \mathrm{s}$ value before the simulation ends, that is supposed to be established on the whole reach. 
Figure 9 shows the mean velocity variation at the chosen points.

In the lower part of the reach, the maximum discharge value, around $20000 \mathrm{~m}^{3} / \mathrm{s}$, has not been attained before the simulation ends. Since it would be very computer time consuming to continue the simulation to bring the $20000 \mathrm{~m}^{3} / \mathrm{s}$ to the end of reach where the most populated areas are located, a second simulation [3] for the lower part of the reach with an upstream constant discharge of $20000 \mathrm{~m}^{3} / \mathrm{s}$ has been done. This study [3] gives the maxima of discharge and elevation at the sea entrance and neighboring cities providing the results needed to delimitate the flood boundaries corresponding to the impact of the multiple dam break on the whole river system to its full extent.

Table 2 and figure $10(a)$ show the evolution of the wave front, time of arrival versus distance during the simulation. Column (1) shows the kilometer sites considered, column (2) gives the front velocity in meters per second, columns (3) and (4) the elevation upstream and downstream of the front respectively, column (5) the front height in meters, column (6) the arrival time of the wave front in seconds and column (7) indicates whether the bed is dry or wet.

Figure 10(b) shows the time of occurrence of the maximum stage along the river, the discontinuities are caused by the presence of hydraulic jumps that can move up and down as the simulation goes on. The average error due to the numerical scheme was of $\pm 1.0 \%$ on the water volume the model making the check automatically to see what is the error introduced by the numerical scheme.

For the dry bed case, the front height is not defined since a parabolic shape is assumed [16], from column (2) of the front velocities ; we can correlate the low velocities of the front with the dry bed and the high values with the wet bed. For this study the front velocity over the dry bed part of the reach varies typically between 1.67 and $3 \mathrm{~m} / \mathrm{s}$ while for the wet bed the values of the front velocity are around $10 \mathrm{~m} / \mathrm{s}$ and over. All these values depend on slope, roughness, etc.

\section{Verification of results}

Since the river has never carried $20000 \mathrm{~m}^{3} / \mathrm{s}$, full verification of river stages was not possible. Nevertheless by the existing gaging stations it was possible to verify the accuracy of the simulation for much smaller discharges.

The gaging station at dam number 7 recorded $5048 \mathrm{~m}^{3} / \mathrm{s}$ as the highest discharge. Verification of this level with the value obtained by the simulation was $20 \mathrm{~cm}$ higher ; considering that the simulation gives the rising stage and that the stage is lower for the same discharge than on the falling limits of the hydrograph, this could be considered a reasonable result.

So from here, we see that the simulated discharge will be four-fold the biggest discharge ever recorded.

In order to verify the unsteady water profiles as well as to have specific information on the dams backwater curves when each structure is overtopped with the $20000 \mathrm{~m}^{3} / \mathrm{s}$ discharge, the dam crest acting like a weir, a standard back water program HEC-2 was used [3] to obtain the stage upstream of each dam. Far away from each dam, where the dam back water effect is negligible, the results of the steady and unsteady simulation were compared: the steady profiles were on the average $10 \mathrm{~cm}$ higher than the profiles of the unsteady simulation for the same discharge.

\section{General remarks and summary}

The study described here concerns the eight dams existing on a particular river as well as four tributaries.

The model used was of the explicit type [1, 5]. Existing hydraulic jumps were considered as such. The relative advantage of the explicit scheme to model the hydraulic jumps with respect to an implicit [5] one is counterbalanced by a much higher computer cost.

This study used the wave front as a mobile downstream boundary condition and according to the chosen hypothesis, each dam was supposed to fail as soon as the wave front reaches the structure.

To this point some comments on the wave front behaviour seems on line.

The great influence of the roughness on the front velocity is an accepted fact $[1,8,9,12]$ whether the flow takes place on a dry or wet bed.

Considering the influence of roughness on wave front height, the consensus does not exist [12]. A clear difference must be made between propagation on a dry bed or a wet bed. For the dry bed case, it appears that the increase in roughness increases the wave front height [16] if the very steep parabolic profile could be almost assimilated in some way to a front.

When we consider propagation of the wave front over a wet bed, we have the shock equations to describe the phenomena $[1,7]$ and contrary to the dry bed case some authors [12] feel that the influence of the roughness is negligible, on this study, the existence of the wave front to define the downstream boundary condition is needed, so when the front reaches reservoir of dam number 7 kilometer 279 of the reach, the front vanishes, i.e. the front height becomes zero before reaching the dam to be breached. The way to avoid this, was to increase temporarily the roughness of the reservoir. Then, the front height increased and the front was able to reach the dam and break it, this allowing the simulation to continue. So, from this it looked that channel roughness increases in dam break analysis does increase the wave front height.

Hunt [12] in a recent study concluded that the roughness has no influence on the front height. His conclusion is valid when a kinematic model is used but when the full Saint-Venant equations are used [12] as well as analysing experimental data $[8,9]$, there is an increasing phase shift between time of arrival of the wave front to a downstream location and the time of occurrence of the peak discharge at the same location. This phase shift which is zero at the site of the breached dam (total and instantaneous failure had been assumed) increases as one moves downstream. This phenomenon 


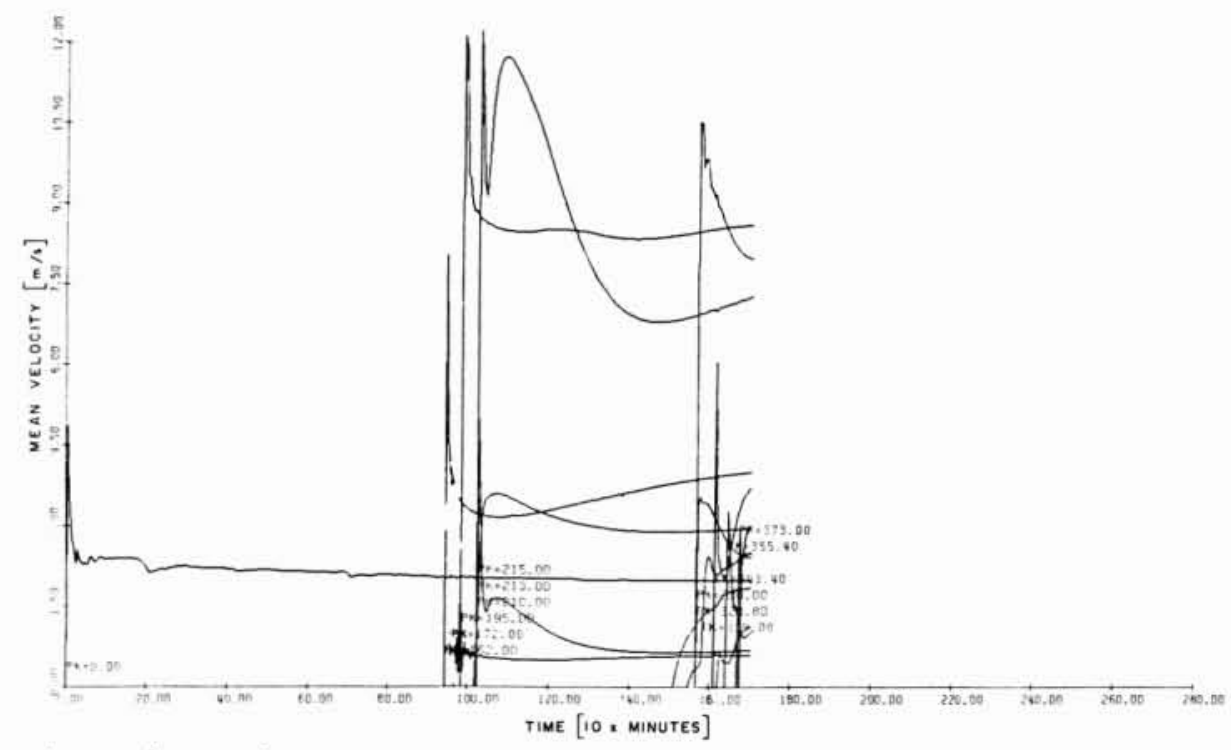

9. Velocity versus time at chosen points.

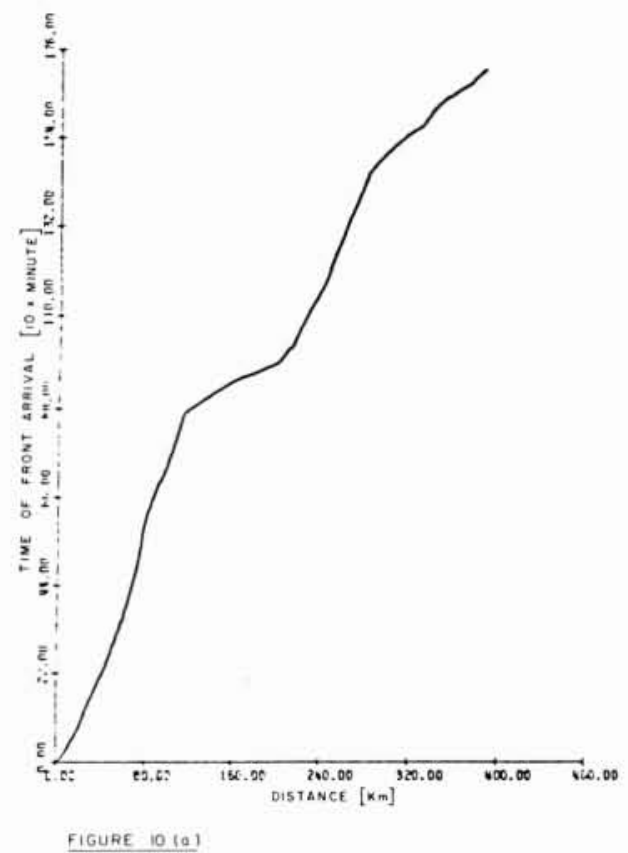

10(a). Arrival front time versus reach length.

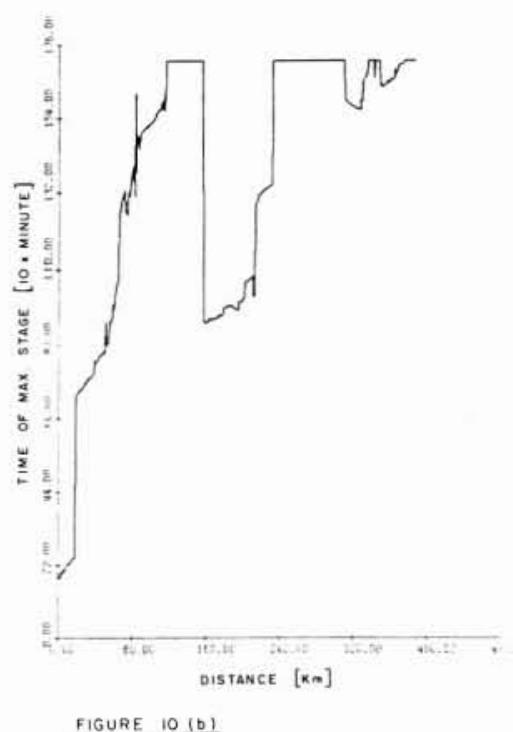

10(b). Time of occurrence of maximum stage versus reach length.

Table 2. Velocity and front height of the wave tip every 20 kilometers.

\begin{tabular}{|c|c|c|c|c|c|c|}
\hline $\begin{array}{c}\text { Front location } \\
\text { on kilometers } \\
\text { (1) }\end{array}$ & $\begin{array}{c}\text { Front velocity } \\
\text { in } \mathrm{m} / \mathrm{s} \\
\text { (2) }\end{array}$ & $\begin{array}{c}\text { Upstream front ele- } \\
\text { vat ion on metres } \\
\text { (3) }\end{array}$ & $\begin{array}{c}\text { Downstream front ele- } \\
\text { vation on metres } \\
\text { (4) }\end{array}$ & $\begin{array}{c}\text { Front eight } \\
\text { on metres } \\
\text { (5) }\end{array}$ & $\begin{array}{c}\text { Arrival time } \\
\text { of the front } \\
\text { on seconds } \\
(6)\end{array}$ & $\begin{array}{l}\text { Remarks } \\
\text { (7) }\end{array}$ \\
\hline 0.0 & 0 & 405.08 & 381.00 & 24.80 & 0 & Start of simulation \\
\hline 20.0 & 3.09 & - & - & - & 4882 & Dry bed \\
\hline 40.0 & 2.88 & - & - & - & 12599 & Dry bed \\
\hline 60.0 & 2.10 & - & - & - & 21299 & Dry bed \\
\hline 80.0 & 1.67 & - & - & - & 35679 & Dry bed \\
\hline 100.0 & 1.81 & - & - & - & 44389 & Dry bed \\
\hline 120.0 & 9.47 & 276.19 & 275.84 & 0.35 & 52749 & Wet bed \\
\hline 140.0 & 9.29 & 276.06 & 275.84 & 0.22 & 54859 & Wet bed \\
\hline 160.0 & 12.25 & 276.04 & 275.82 & 0.22 & 56849 & Wet bed \\
\hline 180.0 & 13.99 & 199.07 & 192.94 & 6.13 & 58078 & Wet bed \\
\hline 200.0 & 10.52 & - & - & - & 59512 & Dry bed \\
\hline 220.0 & 2.79 & - & - & - & 63395 & Dry bed \\
\hline 240.0 & 2.83 & - & - & - & 69439 & Dry bed \\
\hline 260.0 & 2.28 & - & - & - & 77407 & Dry bed \\
\hline 280.0 & 2.26 & - & - & - & 85679 & Dry bed \\
\hline 300.0 & 6.14 & 102.74 & 102.60 & 0.14 & 90271 & Wet bed \\
\hline 320.0 & 10.11 & 102.68 & 102.60 & 0.08 & 93052 & Wet bed \\
\hline 340.0 & 4.56 & 75.62 & 75.60 & 0.02 & 96236 & Wet bed \\
\hline 360.0 & 8.83 & - & - & - & 98940 & Dry bed \\
\hline 380.0 & 6.81 & 1.28 & 1.20 & 0.08 & 101415 & Wet bed \\
\hline 388.4 & 7.55 & 1.22 & 1.20 & 0.02 & 102639 & End of simulation \\
\hline
\end{tabular}

* On a dry bed the front height is not defined due to its parabolic shape. 
is not accounted for when the simulation is made with a kinematic model, where front arrival and maximum discharge coincide.

The effect of the roughness on the front height reported above, is due to this phase shift. Since front velocity decreases due to the roughness increase [1], the effect of this roughness increase is very much felt on the front which has lower discharges than its back which brings the peak of the flood, so the roughness increase has the effect of reducing the gap between time of front arrival and time of occurrence of the peak. Hence the front discharge increases and so does the front height with an increase in roughness.

The above comments and conclusions are valid only for dam break floods.

\section{Conclusion}

To assess the eventual impact of the dam break flood on the populated areas located at the downstream end of the river, multiple dam break analysis is the only approach since $90 \%$ of the river storage is located in the most upstream reservoir.

The most upstream dam that contains most of the water volume has a natural control and its representative discharge during the simulation is limited to $20000 \mathrm{~m}^{3} / \mathrm{s}$ which means that there is enough water to sustain a 5 day flood. Once this is known and the individual behaviour of the other dams is assessed on the cascade breach simulation, an evaluation of the dynamics of the whole river system as far as dam break is concerned is obtained.

Since the effect of the whole upstream dams is the $20000 \mathrm{~m}^{3} / \mathrm{s}$ discharge, it was possible by a second study [3] to define the flood maps in the lower part of the reach.

In as much as it was possible, verification of state by the existing data and with steady backwater computation [4] was done. By numerical experimentation it was observed [2] that the front height over a wet bed increases with a roughness increase on dam flood waves.

The front velocity depends clearly on bed condition. In general, dry bed gives much lower velocities.

\section{Acknowledgments}

The work described in this paper was carried out as part of a project at the Service Hydraulique, Direction Equipements de production of Hydro-Québec and the paper is published with permission of the Director of Equipements de production of Hydro-Québec (Montreal).

The computer code used in this study was a modified version of the package RUPTURE of E.D.F., the French authority.

The support of Hydro-Québec and the National Research Council of Canada on Science and Engineering is explicitly acknowledged.

\section{References}

[1] Benoist, G. et al., «Calcul des ondes de submersion à l'aval des barrages d'électricité de France ", Prod. of the 15th Congress of the International Association for Hydraulic Research, Istambul, 1973 page 5 1-2-1 (in French).

[2] Carballada, L., Report \#RSM43-80-24, Service Hydraulique, Projet des Centrales, Hydro-Québec, August 1980, Montreal, Quebec, Canada (in French).

[3] Carballada, L., Report \#RSM44-80-24, Service Hydraulique, Projet des Centrales, Hydro-Québec, November 1980, Montreal, Quebec, Canada (in French).

[4] Carballada, L., Report \#RSM43-80-24, Service Hydraulique, Projet des Centrales, Hydro-Québec, December 1980, Montreal, Quebec, Canada (in French).

[5] Carballada, L., « Bris de barrage multiple ", Prod. of the 20th Congress of the International Association for Hydraulic Research, Moscow USSR, September 1983 (in French).

[6] CHEN, C., «Laboratory Verification of a Dam-Break Flood Model ", Journal of the Hydraulics Division, ASCE, Vol. 106, No HY4 Proc. Paper 15324, April 1980, pp. 535556.

[7] Chen, C. and Armbruster, J. T., « Dam Break Wave Model: Formulation and Verification ", Journal of the Hydraulics Division, ASCE, Vol. 106, No HY5, May 1980.

[8] « Floods Resulting from Suddenly Breached Dams - Conditions of Minimum Resistance ", Miscellaneous Paper No 2374, Report 1, United States Army Engineer Waterways Experiment Station, Vicksburg, Miss., Feb. 1960.

[9] « Floods Resulting from Suddenly Breached Dams - Condition of High Resistance ", Miscellaneous Paper No 2-374, Report 2, United States Army Engineer Waterways Experiment Station, Vicksburg, Miss., Nov. 1961.

[10] FrEAD, D. L., « The Development and Testing of a Dambreak Flood Forecasting Model n, Proceedings of Dambreak Flood Routing Model Workshop, U.S. Department of Commerce, National Technical Information Service (PB275347), Oct. 1977, pp. 164-197.

[11] Hunt, B., «Asymptotic Solution for Dam-Break Problem ", Journal of the Hydraulics Division, ASCE, Vol. 108, No HY1, January 1982 and Discussion by Katopodes, N.D. and Ponce, V.M. and Closure by Hunt, B., Journal of Hydraulic Engineering, ASCE, Vol. 109, No 4, April 1983, pp. 639-640.

[12] Hunt, B., «Asymptotic Solution for Dam-Break on Sloping Channels", Journal of Hydraulic Engineering, ASCE, Vol. 109, No 12, December 1983.

[13] Katopodes, N. D. and Schamber, D., « Applicability of Dam-Break Flood Wave Models ", Journal of Hydraulic Engineering, ASCE, Vol. 109, No 5, May 1983.

[14] Ponce, V. M. and Tsivoglove, A. J., « Modeling Grandual Dam Breaches ", Journal of the Hydraulics Division, ASCE, Vol. 107, No HY7, July 1981.

[15] Ritter, A., "The Propagation of Water Waves ", Ver Deutsch Ingenieure Zeitschr, Vol. 36, Part 2, No 33, Berlin, Germany, 1892, pp. 947-954.

[16] Whitham, G. B., « The Effect of Hydraulic Resistance on the Dam-Break Problem n, Proceedings, Royal Society of London, No 1170, Jan. 1955.

Mr. Luis Carballada, Hydro-Québec, place Dupuis, 855 Est, rue Sainte Catherine, Montréal, Québec H2L 4P5 (Canada). 